\title{
CONCEPT ART: RECURSO EDUCACIONAL SOBRE CONCEPT ART DESTINADO A PROFESSORES E ESTUDANTES INTERESSADOS NA ÁREA DE ILUSTRAÇÃO
}

\author{
Letícia Julinski Nunes \\ Universidade Positivo \\ leticiajulinsk@hotmail.com \\ Nadine Aparecida Age \\ Univerdidade Positivo \\ nadine.a.age@gmail.com
}

\author{
Thaísa Cristine de Souza Werner \\ Univerdidade Positivo \\ thaisawerner@gmail.com \\ Gabrielle Grimm \\ Univerdidade Positivo \\ gabihgrimm@gmail.com
}

Resumo: Este projeto de Iniciação Tecnológica visa o desenvolvimento de recursos educacionais, com o intuito de utilizar as possibilidades que as tecnologias da informação proporcionam, aliando essas tecnologias com recursos da linguagem visual para complementar o aprendizado em sala de aula. Um recurso educacional que aponte de maneira concreta (por meio do visual, sonoro, com exemplos práticos) o raciocínio que o professor aborda em sala, ajudará o aluno na construção do conhecimento. Dentro deste contexto, as dificuldades observadas nos alunos envolvem as disciplinas mais teóricas, mas também aquelas em que o conteúdo é dificilmente encontrado. No caso do "Concept art", a maioria dos materiais encontrados são em inglês. Concept art pode ser definido superficialmente como a representação visual de personagens, ambientes e objetos, ou simplesmente a criação de uma atmosfera visual para uso em filmes, videogames, cinema de animação e histórias em quadrinhos (SENNA, 2013), e é um campo em grande crescimento para ilustradores. Referente ao assunto o que se encontra disponível são os Art books, livros que contém o processo de direção de arte das principais produções de grandes estúdios como Pixar e Dreamworks. Esses livros apresentam os sketchs (desenhos iniciais), ilustrações conceituais de personagens, cenários e modelos digitais finalizados destas produções, que servem de fonte para pesquisa iconográfica sobre concept. Porém é fundamental quando se está em busca de aprendizado que se compreenda o conjunto de procedimentos para execução destas ilustrações conceituais. Perceber métodos, técnicas, ferramentas acompanhadas dos exemplos visuais também são de extrema importância para que o aluno construa esse repertório e aprimore suas técnicas. 0 recurso educacional desenvolvido no projeto tem por objetivo abordar o processo de Concept Art e que possa ser utilizado por alunos, por professores, ou por interessados nesse universo. Para isso foi realizado o levantamento e organização do material teórico e uma pesquisa documental sobre o conteúdo. Concluída a parte teórica, iniciaram-se as ilustrações que irão auxiliar na compreensão do 
conteúdo. Decidiu-se durante o projeto que o material educacional a ser desenvolvido seria um E-book. Este foi escolhido por tratar-se de uma plataforma de fácil acesso e que suporta diversas mídias como vídeos, áudios e links para outras páginas ou materiais. Depois de escolhida a plataforma de apoio, o e-book foi produzido, contando com uma linguagem mais próxima do público-alvo e com ilustrações para ajudar na compreensão. Foi realizado um arquivo em PDF que será disponibilizado em sites e livrarias gratuitamente, pois espera-se que o material possa ser utilizado por alunos e professores a fim de facilitar o acesso e a construção do conhecimento. $O$ recurso educacional pode ser consultado pelos alunos para dirimir dúvidas, mas também pode ser utilizado como recurso visual em sala de aula pelo professor. O projeto reuniu um conteúdo que era muito fragmentado, e utilizou os recursos da linguagem visual para ilustrar e disponibilizar o acesso a esse conteúdo.

Palavras-chave: Recurso Educacional, Design, llustração, Concept-art, Criação de personagens 